\title{
Crouzon syndrome-acanthosis nigricans syndrome
}

INSERM

\section{Source}

INSERM. (1999). Orphanet: an online rare disease and orphan drug data base. Crouzon syndrome-acanthosis nigricans syndrome. ORPHA:93262

Crouzon syndrome with acanthosis nig ricans (CAN) is a very rare, clinically heterogeneous form of faciocraniostenosis with Crouzon-like features and premature synostosis of cranial sutures (Crouzon disease, see this term), associated with acanthosis nigricans (AN; see this term). 